\title{
Association of p53 codon 72 Arg >Pro polymorphism and risk of cancer in Iranian population: A systematic review and meta-analysis
}

\author{
Daem Roshani ${ }^{1 *}$, Alina Abdolahi ${ }^{2}$, Shima Rahmati ${ }^{2}$ \\ Received: 14 Nov 2016 \\ Published: 27 Dec 2017
}

\begin{abstract}
Background: Different studies have investigated the association between p53 codon 72 Arg $>$ Pro polymorphism and cancer risk. Because of the lack of consensus of the results in individual studies, we conducted this meta-analysis by pooling all currently available case-control studies to estimate the effect of p53 codon 72 Arg/Pro polymorphism on cancer susceptibility in Iranian population.

Methods: A comprehensive search was undertaken and primary data from all peer-reviewed journals indexed in PubMed, Google Scholar, Scopus, Magiran, Scientific Information Databank (SID), Iran Medex, and CAB abstract electronic were used to conduct this meta-analysis. We considered some exclusion and inclusion criteria to select the articles. Statistical heterogeneity was explored using the I-square. Publication bias was assessed graphically and statistically by Begg's funnel plot and Egger test. All statistical analyses were performed using StatsDirect software and a two- tailed test. P-value less than 0.05 was considered statistically significant for any test.

Results: Our dataset, which included 35 case-control studies, consisted of 2426 cancer cases and 2928 controls. Pooled OR and $95 \% \mathrm{CI}$ indicated that codon $72 \mathrm{Arg}>$ Pro polymorphism was not associated with odds of developing cancer among Iranian population in the dominant model (Pro/Pro+Arg/Pro vs. Arg/Arg: $\mathrm{OR}=0.96,95 \% \mathrm{CI}=0.74$ to $1.24 \mathrm{chi} 2=0.06, \mathrm{p}=0.8$ ). Moreover, no significant association was detected in variant allele (Pro vs Arg: $\mathrm{OR}=1.075,95 \% \mathrm{CI}=0.91$ to 1.25), homozygous (Pro/Pro vs Arg/Arg: $\mathrm{OR}=0.91195 \% \mathrm{CI}=0.66$ to 1.25 ), and heterozygous (Arg/Pro vs $\mathrm{Arg} / \mathrm{Arg}$ : $\mathrm{OR}=0.84,95 \% \mathrm{CI}=0.7$ to 1 ).

Conclusion: Our study revealed that p53 codon 72 Arg>Pro polymorphism was not associated with overall cancer odds in Iranian population.
\end{abstract}

Keywords: Meta-analysis, Cancer, p53, Iran

Copyright $\odot$ Iran University of Medical Sciences

Cite this article as: Roshani D, Abdolahi A, Rahmati Sh. Association of p53 codon 72 Arg $>$ Pro polymorphism and risk of cancer in Iranian population: A systematic review and meta-analysis. Med J Islam Repub Iran. 2017 (27 Dec);31:136. https://doi.org/10.14196/mjiri.31.136

\section{Introduction}

About 12.7 million cancer cases and 7.6 million cancer deaths were estimated to occur in 2008 worldwide. Cancer is one of the most common causes of death worldwide (1). Cancer incidence rate depends on multi-environmental factors including geographical region, habitats, life style, and genomic variation (2). TP53 is a tumor suppressor gene, containing 11 exons and 10 introns, located on chromosome $17 \mathrm{p} 13$ (3). TP53 gene encodes p53 protein that binds to promoters and introns of genes and involves many proteins including components of the basal transcriptional apparatus, histone acetyl transferees, and other transcriptional cofactors, which are essential for transcrip-

Corresponding author: Dr Daem Roshani, d.roshani@muk.ac.ir

1. Social Determinants of Health Research Center, Kurdistan University of Medical Sciences, Sanandaj, Iran.

2. Cellular and Molecular Research Center, Kurdistan University of Medical Sciences, Sanandaj, Iran. tional initiation (4-6). This protein function results in gene transcription, DNA repair, apoptosis, senescence, or temporary cell cycle arrest under a variety of circumstances and mechanisms including genotoxic stresses, oncogenic signaling, and hypoxia $(5,7)$.

The lack of proper function of $\mathrm{p} 53$ is associated with many types of cancer including cervical, prostate, gastric, breast, endometrial, hepatocellular, and ovarian carcinomas (8-15). Single nucleotide polymorphisms (SNPs) are the most common form of tumor- associated mutations in p53. Among10 polymorphisms that are described in this gene, $\mathrm{G}$ to $\mathrm{C}(\mathrm{Arg} / \mathrm{Pro})$ transversion in Codon 72 in Exon

$\uparrow$ What is "already known" in this topic:

Meta-analysis is a useful statistical tool for combining the results from individual studies to provide results that are more trustworthy.

$\rightarrow$ What this article adds:

Codon 72 Arg $>$ Pro polymorphism was not associated with odds of developing cancer among Iranian population. 
4 is a common polymorphism and is associated with an increased risk of various types of cancer (16). The p53 P72 allele is weaker than the R72 allele in inducing apoptosis and suppressing cellular transformation, but appears to be better at initiating senescence and cell cycle arrest $(17,18)$. Jiang et al. performed a meta- analysis by pooling 17 publications to evaluate the possible effect of the p53 Codon 72 Arg/Pro polymorphism on oral cancer risk. They found no significant association between p53 Codon 72 Arg/Pro polymorphism and risk of oral cancer (19). Wang et al. performed a meta-analysis by pooling 14 publications and suggested that the p53 Codon $72 \mathrm{Arg} / \mathrm{Pro}$ polymorphism is a risk factor for lung cancer in the Asian population(20). Zhou et al. performed a meta-analysis by pooling 12 publications and suggested that the p53 Codon 72 polymorphism may be associated with gastric cancer among Asians, and they further indicated that difference in genotype distribution may be associated with the location, stage, and histological differentiation of gastric cancer(21). Also, Irshad et al. performed a meta-analysis by pooling 5 publications, and they found that the Codon 72 Arg $>$ Pro polymorphism of the p53 gene might not contribute to cancer susceptibility in the Saudi population (22). As discussed earlier, previous case-control studies have investigated the association between mentioned polymorphism and cancer risk in the Iranian population. Due to the small sample size and low statistical power in each of the performed studies, the results were not reliable enough to determine the effect of this polymorphism on cancer susceptibility. Meta-analysis is a useful statistical tool for combining the results from individual studies to provide more trustworthy results (23). To date, no metaanalysis has been conducted on the Iranian population to evaluate this association. Therefore, we conducted this meta-analysis to pool all the published studies and determine the association between p53 Codon $72 \mathrm{G}>\mathrm{C}$ polymorphism and cancer risk.

\section{Methods \\ Search Strategy for Identification of Studies}

We followed "PRISMA" 2012 checklist criteria for meta-analysis. To cover overall publications, we used the following keywords: "p53 gene polymorphism", "p53 gene mutation", "p53 gene variation", "p53 codon 72 Arg>Pro", "Carcinoma" and "cancer risk", and "in Iranian population". The full texts of all relevant studies were analyzed carefully to determine whether data on the topic and abstract of interest were intact. Furthermore, the reference lists of the relevant articles and systematic reviews were investigated to ensure that no data were missed. In the selected case-control studies, blood and tissue samples of patients were collected from clinical hospitals and laboratories, and control samples were randomly selected from those who referred to clinical centers, who had no previous history of cancer and no signs and symptoms of malignancy.

\section{Inclusion criteria}

The following criteria were used to select the studies: (1) a case-control design; (2) assessment of the p53 Codon
$72 \mathrm{Arg}>$ Pro and cancer risk in Iranian population; (3) recruiting histologically and pathologically confirmed cancer patients and healthy controls;(4) adequate genotyping data so that odds ratios (24) with $95 \%$ confidence intervals (CIs) could be calculated; (5) the selected studies had to be conducted on human samples; and (6) inclusion of genotype frequency of cases and controls.

\section{Exclusion criteria}

Exclusion criteria were as follow: (1) not enough information on the distribution of p53 Codon 72 polymorphism; (2) case-only studies; (3) duplicated publications; (4) the studies that used cell line and animal subjects; (5) genotype frequency missing; (6) studies that investigated the levels of p53 mRNA expression; and (7) review articles.

\section{Information sources}

The retrieved studies were searched through the PubMed, Google Scholar, Scopus, Magiran, Scientific Information Databank (SID), Iran Medex, and CAB abstract electronic databases. Publications in English and Persian languages from 2006 to December 2016 were included in this manuscript.

\section{Extracted Information}

Two researchers independently extracted the crude data according to the inclusion and exclusion criteria listed above to prove the validity of the retrieved information. The prepared data included the first author's name, date of publication, type of cancer, ethnicity, number of cases and controls, and genotype frequencies. Disputes were settled by referring to a third researcher.

\section{Statistical analysis}

The association between p53 Codon 72 Arg>Pro polymorphism and cancer risk was obtained by pooling odds ratio $(\mathrm{OR})$ and $95 \%$ confidence intervals $(\mathrm{CI})$. In the present study, estimation of the pooled effect was based on the weighted average from the results of the individual studies. Weighted average for each study was calculated based on sample size and variance of samples.

The random-effects (DerSimonian and Laird method) and fixed effect models (Mantel and Haenszel method) were applied. I $\mathrm{I}^{2}$ statistics and Cochran's Q statistic $(\mathrm{p}<0.10)$ were used to check out heterogeneity assumption $\left(\mathrm{I}^{2}\right.$ static is the percentage of the observed total variation across studies that are due to heterogeneity rather than chance). A value of $0 \%$ indicates no observed heterogeneity, and larger values show increasing heterogeneity. Q is the weighted of squares on a standardized scale, which is reported with a p-value, with low p-values indicating the presence of heterogeneity. If $p<0.05$, the results were pooled by the random-effects model, otherwise, fixed effect model was used.

To evaluate the publication bias among the included studies, Begg's funnel plot and Egger's linear regression test were performed. The Hardy-Weinberg equilibrium was calculated in the control groups using a goodness of fit test for each study. All the statistical analyses were 
performed using Stats Direct software and a two- tailed test. P- value less than 0.05 was considered statistically significant for any test.

\section{Results}

Characteristics of publications and meta-analysis databases

In this study, 157 relevant articles were recovered by literature search. However, considering the inclusion and exclusion criteria, 67 articles were excluded because they were not relevant; moreover, 58 articles were excluded for being duplicates, not being performed on human subjects, and being review articles. After careful screening, 32 eli- gible case-control studies on the association between p53 Codon $72 \mathrm{Arg}>$ Pro polymorphism and cancer risk in the Iranian population (Fig. 1) were selected. Information including authors, date of publication, cancer type, distribution of genotypes (cases and controls), and the HardyWeinberg equilibrium are presented in Table 1.

\section{Evaluation of heterogeneity}

To analyze heterogeneity among the studies, Q test, $\mathrm{I}^{2}$ statistics, and heterogeneity were noticed in all the 5 genetic models. The random effects model was used to calculate the odds ratio and $95 \%$ confidence interval (Table 2).

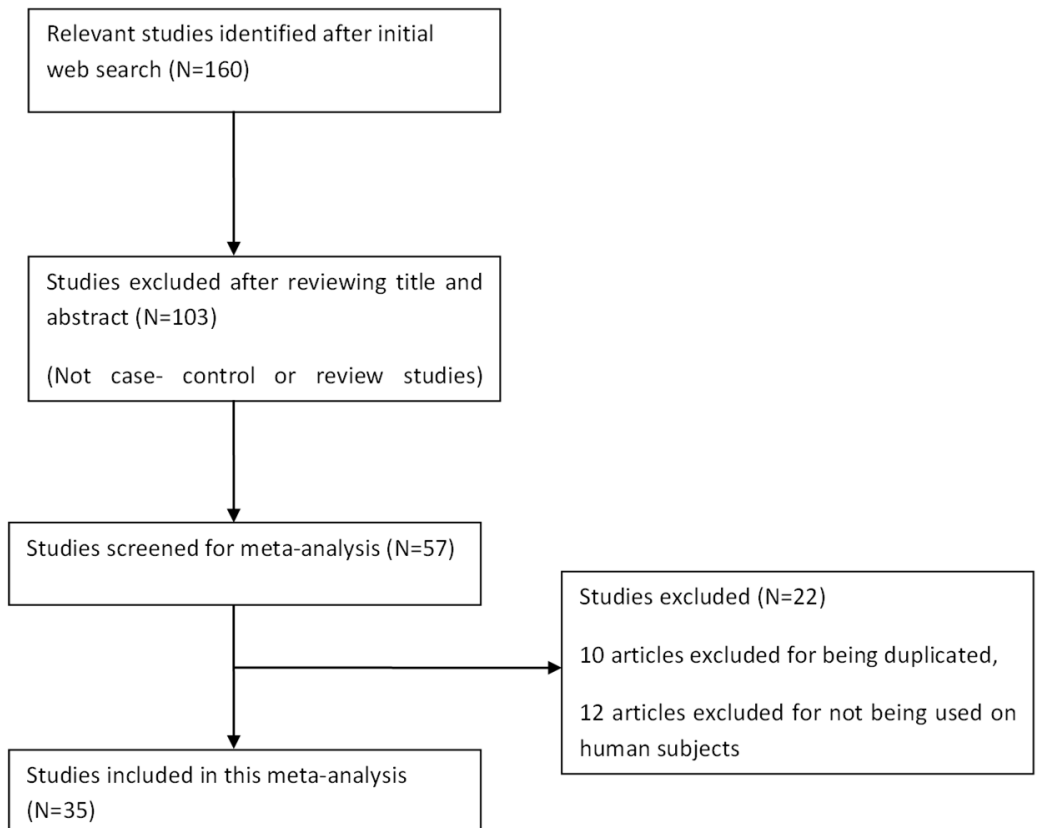

Fig. 1. PRISMA flow diagram: Demonstrating identification and study selection process

Table 1. Distribution of p53 codon 72 Arg $>$ Pro polymorphism included in the meta- analysis

\begin{tabular}{|c|c|c|c|c|c|c|c|c|c|}
\hline \multirow{3}{*}{ Authors } & \multirow{3}{*}{ Years } & \multirow{3}{*}{ Cancer Type } & \multicolumn{3}{|c|}{ Control } & \multicolumn{3}{|c|}{ Case } & \multirow{3}{*}{$\frac{\text { HWE }}{\text { P-value }}$} \\
\hline & & & & Genotype & & & Genotype & & \\
\hline & & & Arg/Arg & Arg/Pro & Pro/Pro & Arg/Arg & Arg/Pro & Pro/Pro & \\
\hline Zahra Eyedian & 2016 & Lung & 88 & 88 & 24 & 20 & 83 & 97 & 0.781 \\
\hline Fatemeh Keshavarz & 2016 & Breast & 20 & 38 & 25 & 10 & 45 & 35 & 0.46 \\
\hline FarinazBehfarjam & 2015 & Prostate & 35 & 44 & 17 & 68 & 21 & 7 & 0.624 \\
\hline SahArgohari- & 2015 & Breast & 22 & 54 & 28 & 51 & 31 & 22 & 0.668 \\
\hline Mehdi Nikbahk & 2015 & CML & 16 & 22 & 7 & 9 & 21 & 15 & 0.901 \\
\hline Hosseini-Asl & 2015 & Gastric & 18 & 21 & 2 & 13 & 19 & 9 & 0.182 \\
\hline MinooYaghmae & 2015 & UterineLeiomyoma & 53 & 72 & 24 & 36 & 65 & 38 & 0.956 \\
\hline Mehdi Nikbakht & 2015 & AML & 7 & 48 & 4 & 20 & 36 & 3 & 0.000 \\
\hline Robab Sheikh & 2014 & Breast & 51 & 88 & 41 & 72 & 76 & 32 & 0.7968 \\
\hline Mohammad Taheri & 2014 & Gastric & 30 & 50 & 18 & 56 & 44 & 26 & 0.722 \\
\hline RoghayehDehghan & 2014 & Thyroid & 8 & 24 & 8 & 4 & 22 & 14 & 0.205 \\
\hline Rahim Golmohammadi & 2013 & Breast & 75 & 90 & 40 & 83 & 109 & 29 & 0.146 \\
\hline Boyajian & 2013 & Esophageal & 38 & 37 & 17 & 36 & 36 & 15 & 0.171 \\
\hline MasomehFaghani & 2012 & Colorectal & 162 & 217 & 86 & 34 & 47 & 10 & 0.376 \\
\hline Mohammad Ali & 2012 & Breast & 5 & 13 & 2 & 12 & 7 & 1 & 0.140 \\
\hline Mohammad Ali & 2012 & Thyroid & 19 & 40 & 41 & 16 & 42 & 41 & 0.111 \\
\hline Abbas Doosti & 2011 & Breast & 41 & 29 & 19 & 55 & 64 & 10 & 0.003 \\
\hline Abbas Doosti & 2011 & Prostate & 44 & 63 & 16 & 49 & 63 & 20 & 0.372 \\
\hline Mehdi Nikbahk & 2011 & Skin & 58 & 77 & 28 & 46 & 63 & 23 & 0.777 \\
\hline Mehdi Nikbahk & 2011 & Skin & 36 & 82 & 22 & 52 & 70 & 13 & 0.0301 \\
\hline Abbas Doosti & 2011 & Colorectal & 6 & 11 & 3 & 8 & 10 & 2 & 0.575 \\
\hline Mohammad Mazani & 2011 & Gastric & 27 & 58 & 15 & 6 & 88 & 10 & 0.07 \\
\hline Barzegar & 2011 & Gastric & 31 & 57 & 12 & 31 & 48 & 21 & 0.067 \\
\hline
\end{tabular}




\begin{tabular}{|c|c|c|c|c|c|c|c|c|c|}
\hline \multicolumn{10}{|l|}{ Cntd. Table 2} \\
\hline Zahra Mojtahedi & 2010 & Head and Neck & 2 & 85 & 27 & 49 & 78 & 18 & 0.011 \\
\hline Zahra Mojtahe & 2010 & Gastric & 1 & 35 & 36 & 14 & 37 & 36 & 0.160 \\
\hline Zahra Mojtahe & 2010 & Colorectal & 4 & 56 & 14 & 40 & 57 & 15 & 0.480 \\
\hline NasrinGhasem & 2009 & Endometrial & s & 10 & 1 & 9 & 9 & 2 & 0.394 \\
\hline Mehdi Nikbahk & 2009 & Colorectal & 5 & 77 & 28 & 28 & 54 & 10 & 0.777 \\
\hline Masoud Kazemi & 2009 & Breast & 1 & 48 & 0 & 6 & 30 & 6 & 0.001 \\
\hline Mehdi Nikbahk & 2008 & Colorectal & 2 & 21 & 7 & 2 & 15 & 13 & 0.066 \\
\hline MasomehFaghanin & 2008 & Breast & 5 & 111 & 24 & 74 & 98 & 15 & 0.002 \\
\hline ParvizDeihim & 2008 & Oral squamous cell & 5 & 66 & 32 & 35 & 38 & 11 & 0.202 \\
\hline BaharakKhadang & 2007 & Breast & 3 & 50 & 19 & 19 & 31 & 10 & 0.821 \\
\hline Abdulmohammad & 2006 & Skin & 7 & 113 & 61 & 97 & 101 & 52 & 0.142 \\
\hline SeyedAlireza & 2006 & Lung & 1 & 51 & 14 & 29 & 49 & 2 & 0.013 \\
\hline \multirow{2}{*}{\multicolumn{2}{|c|}{ Comparison }} & \multicolumn{3}{|c|}{ Heterogeneity analysis } & \multicolumn{4}{|c|}{ Egger's linear regression test } & \multirow[t]{2}{*}{ Models } \\
\hline & & Q & $P$ & $\mathrm{I}^{2}(\%)$ & Intercept & & \multicolumn{2}{|r|}{$\bar{P}$} & \\
\hline \multicolumn{2}{|l|}{ Pro vs. Arg } & 58.38 & 0.005 & 41.8 & -0.76 & $(-2.3$ & \multicolumn{2}{|r|}{0.33} & Random \\
\hline \multicolumn{2}{|l|}{ Pro/Pro vs. Arg/Arg } & 153.6 & 0.000 & 77.9 & -0.15 & $(-2.1$ & \multicolumn{2}{|r|}{0.88} & Random \\
\hline \multicolumn{2}{|l|}{ Arg/Pro vs. Arg/Arg } & 91.87 & 0.000 & 63 & 0.26 & $(-1.5$ & \multicolumn{2}{|r|}{0.76} & Random \\
\hline \multicolumn{2}{|c|}{ Pro/Pro + Arg/Pro vs. Arg/Arg } & 164.2 & 0.000 & 79.3 & 0.88 & $(-1.4$ & \multicolumn{2}{|r|}{0.45} & Random \\
\hline \multicolumn{2}{|c|}{ Pro/Pro vs. Arg/Arg+ Arg/Pro } & 126.6 & 0.000 & 73.2 & -0.11 & $(-2$ & & 0.9 & Random \\
\hline
\end{tabular}

The association between p53 codon 72 Arg>Pro polymorphism and cancer risk

To measure the association between p53 Codon 72 Arg $>$ Pro polymorphism and cancer odds, all the 35 studies were pooled together (2426 cancer cases and 2928 controls). Pooled OR and 95\% CI indicated no association between p53 Codon 72 Arg $>$ Pro polymorphism and cancer odds in variant allele (Pro vs. Arg: $\mathrm{OR}=1.075$, $95 \% \mathrm{CI}=0.91$ to $1.25, \mathrm{chi}^{2}$ (test odds ratio differs from 1 ) $=0.83, \mathrm{p}=0.36$ ) and homozygous (Pro/Pro vs. Arg/Arg: $\mathrm{OR}=0.911,95 \% \mathrm{CI}=0.66$ to $\left.1.25, \mathrm{chi}^{2}=0.32, \mathrm{p}=0.57\right)$. Similarly, recessive genetic model and dominant model were not associated with an increased odds of developing cancer (Pro/Pro vs. Arg/Arg+ Arg/Pro: OR= 0.91, $95 \% \mathrm{CI}=0.72$ to $\left.1.16, \mathrm{chi}^{2}=0.49, \mathrm{p}=0.48\right),(\mathrm{Pro} / \mathrm{Pro}+\mathrm{Arg} /$

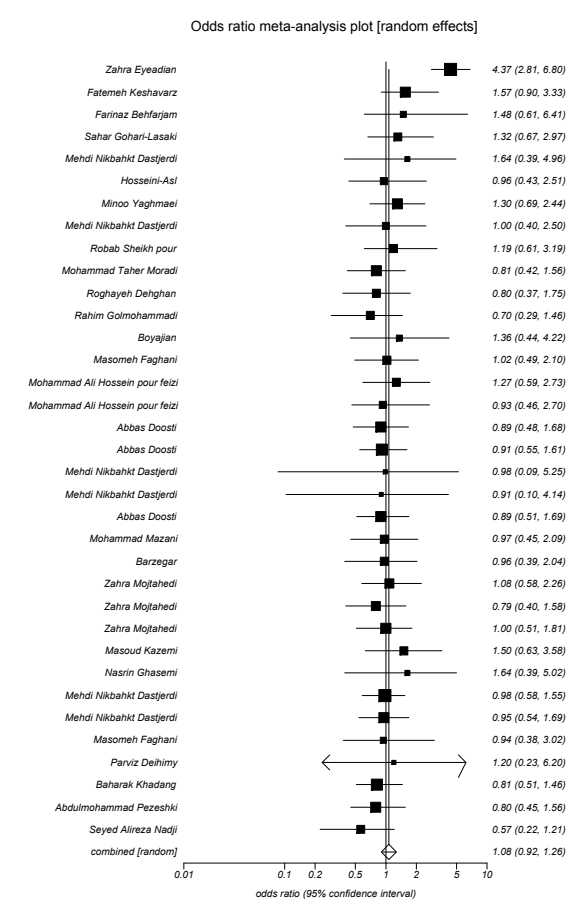

Fig. 2. Forest plot of odds ratio with $95 \% \mathrm{CI}$ of overall cancer risk associated with $\mathrm{p} 53$ codon $72 \mathrm{Arg}>$ Pro polymorphism for allele model
Pro vs. Arg/Arg: $\mathrm{OR}=0.96,95 \% \mathrm{CI}=0.74$ to $1.24, \mathrm{chi}^{2}=$ $0.06, \mathrm{p}=0.8)($ Figs. 2-6).

\section{Publication bias}

Begg's funnel plot and Egger's linear regression test were used to evaluate publication bias the included studies. The appearance of the shape of funnel plot and Egger's linear regression test did not show any evidence of publication bias among all comparison models (Table 2 and Figs. 7-11).

\section{Sensitivity analysis}

We performed sensitivity analysis to evaluate the effect

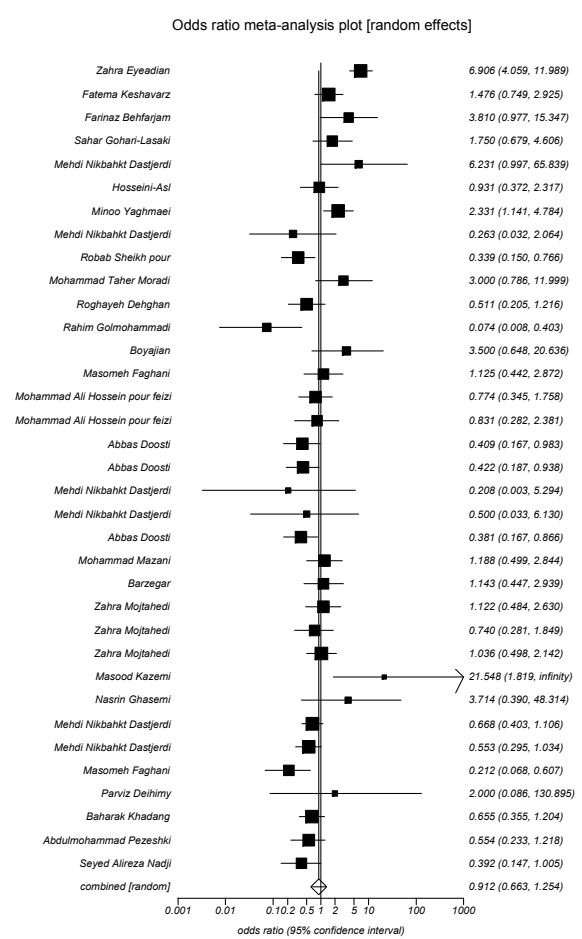

Fig. 3. Forest plot of odds ratio with $95 \%$ CI of overall cancer risk associated with p53 codon $72 \mathrm{Arg}>$ Pro polymorphism for homozygous model 


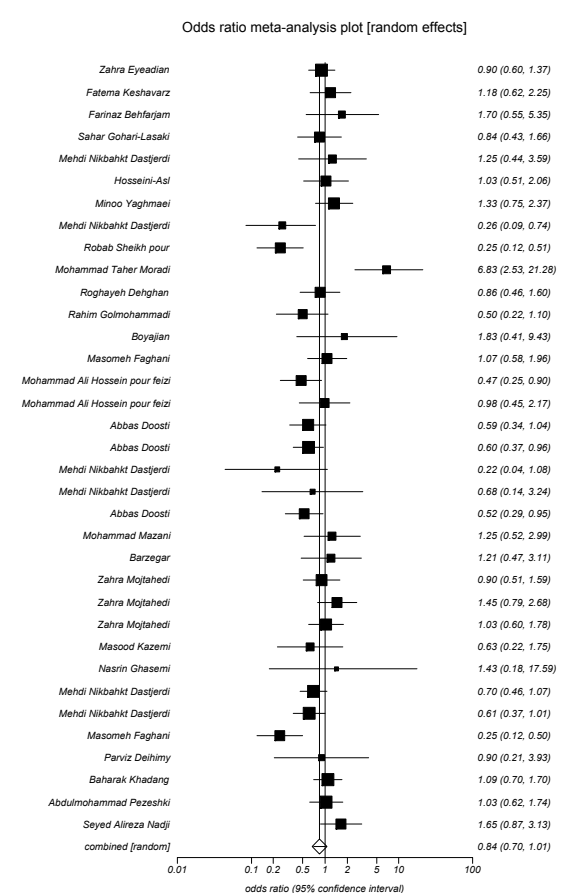

Fig. 4. Forest plot of odds ratio with $95 \%$ CI of overall cancer risk associated with $\mathrm{p} 53$ codon $72 \mathrm{Arg}>$ Pro polymorphism for heterozygous model

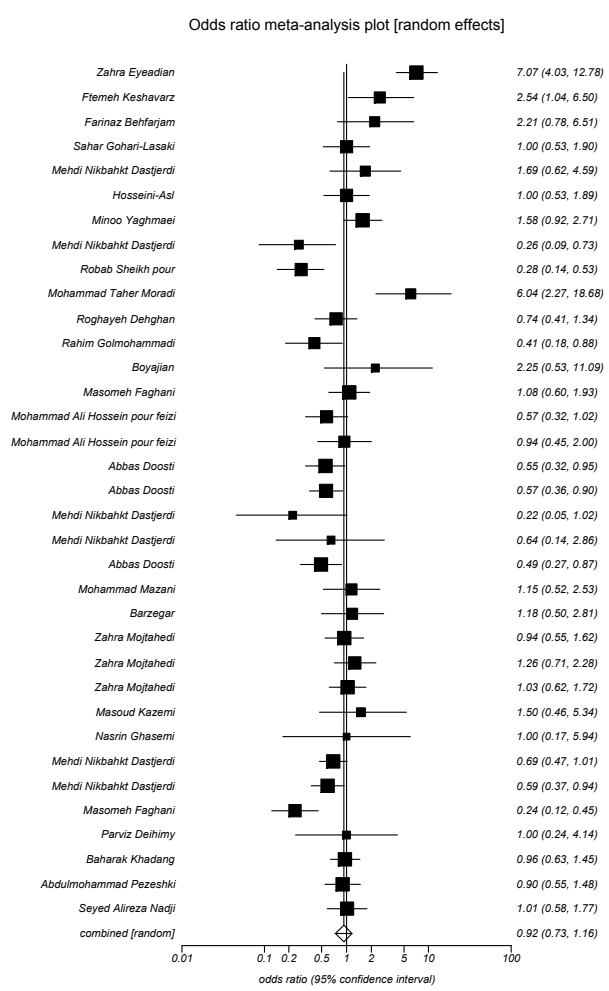

Fig. 5. Forest plot of odds ratio with $95 \% \mathrm{CI}$ of overall cancer risk associated with $\mathrm{p} 53$ codon $72 \mathrm{Arg}>\mathrm{Pro}$ polymorphism for recessive model

of each study included in the present meta- analysis. The results of meta- analysis revealed that pooled ORs were generally similar in all the 5 models.

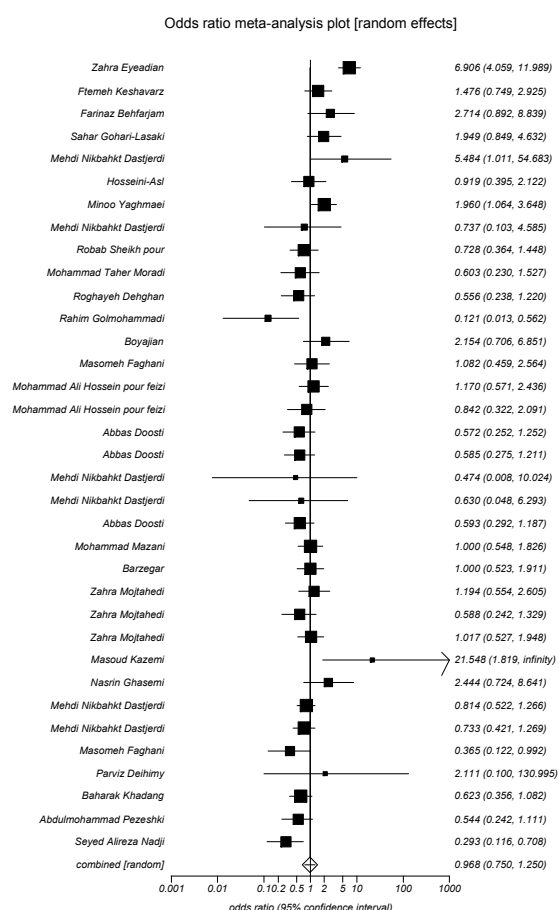

Fig. 6. Forest plot of odds ratio with $95 \% \mathrm{CI}$ of overall cancer risk associated with p53 codon $72 \mathrm{Arg}>$ Pro polymorphism for dominant model

\section{Discussion}

Several epidemiological studies have indicated that cancer is a multi-factorial disease and that nutrition, use of

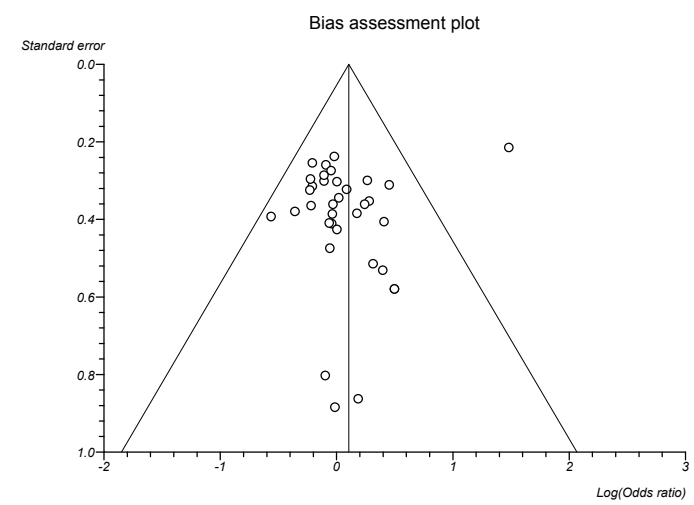

Fig. 7. Funnel plot detecting biases in the identification and selection of studies for allele dominant model

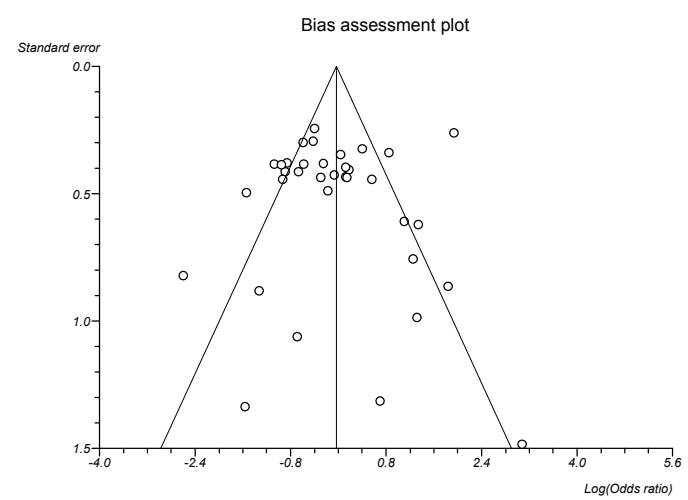

Fig. 8. Funnel plot detecting biases in the identification and selection of studies for homozygous dominant model 


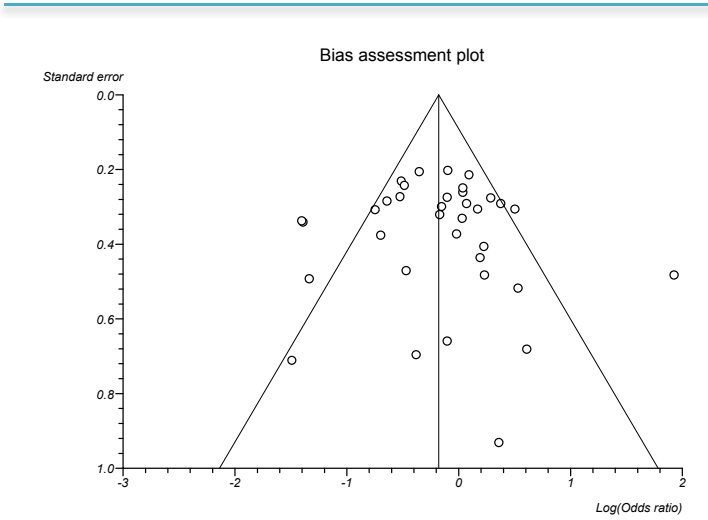

Fig. 9. Funnel plot detecting biases in the identification and selection of studies for heterozygous dominant model

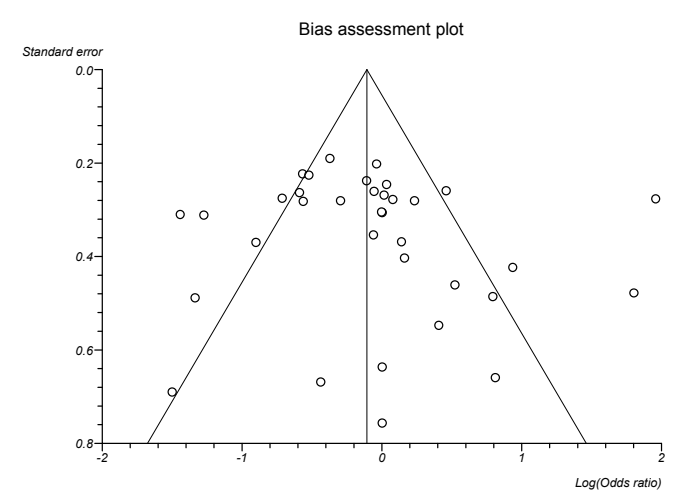

Fig. 10. Funnel plot detecting biases in the identification and selection of studies for recessive dominant model

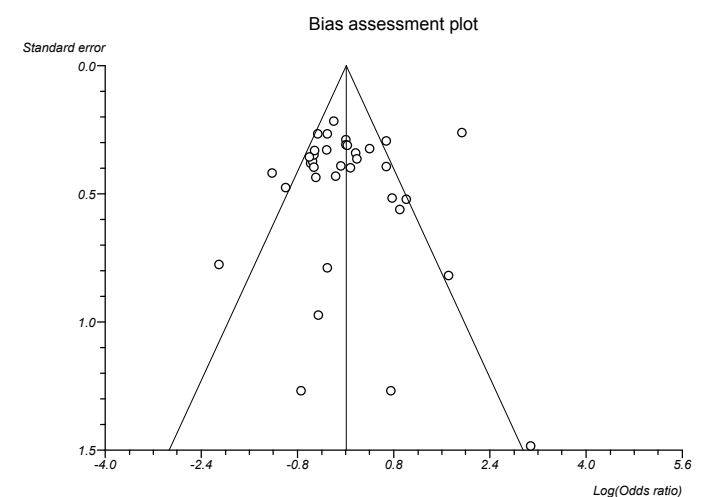

Fig. 11. Funnel plot detecting biases in the identification and selection of studies for dominant model

tobacco and/or alcohol, viral infections, genetic factors, and UV exposure are cancer risk factors. Furthermore, some genetic predisposing factors are involved in carcinogenesis. Genetic alteration could occur in oncogenes, tumor suppressors, and growth of regulator genes (25). TP53 is the most important tumor suppressor gene that plays an important role in response to DNA damage, so this is considered as "guardian of the genome". P53 is one of the most frequently mutated genes in human malignancies and more than $50 \%$ of human cancers (26). In addition to mutations, genetic polymorphisms could also have an effect on the P53 function. In particular, P53 Codon 72 (P53c72) single nucleotide polymorphism (SNP), which could result in either arginine (25) or proline (Pro) alleles, creates 3 different genotypes: Arg/Arg, Arg/Pro, and Pro/ Pro (27). The proteins p53Arg72 and p53Pro72 have dissimilar biochemical and biological possessions, for example, dissimilarity in the binding to parts of the transcriptional apparatus and dissimilarity in the initiation of transcription (10). The p53Arg72 protein persuades apoptosis faster and represses alteration more competently than the p53Pro72 protein (27). There have been reports showing possible involvement of P53c72 polymorphism in individuals' susceptibility to cancers including mouth cancer, breast cancer, thyroid cancer, colorectal, and prostate cancer, which seem to have a mutation in this gene $(9,11,13$, 14, 24). The mentioned case-control studies showed the contribution of P53c72 polymorphism to the carcinogenesis although these studies were done with a small sample size and the results from these individual studies lacked consensus. Thus, we performed the current meta-analysis with more number of cases and controls. Furthermore, to our knowledge, this was the first meta-analysis to assess the association of the P53c72polymorphism with cancer susceptibility among Iranian population.

The overall pooled results of this meta-analysis revealed no association between variant allele of p53 c $72 \mathrm{G}>\mathrm{C}$ polymorphism with an increased or decreased cancer odds. Our results demonstrated that the p53 Codon 72 $\mathrm{G}>\mathrm{C}$ polymorphism is not a significant cause of cancer odds among the Iranian population. Also, in the dominant model (Pro/Pro +Arg/Pro vs. Arg/Arg) codon 72 Arg $>$ Pro polymorphism was not associated with a diminished odds of cancer among this population. A number of studies indicated that TP53 Arg72Pro have no influence on breast cancer odds $(9,28)$, colorectal cancer odds(29), and skin cancer odds (30), whereas some other studies revealed an association between this polymorphism with cancer odds; for instance, Doosti et al. reported that homozygous individuals with the Arg allele have a higher odds of developing breast cancer than heterozygote ones (31). Babaei et al. found that cases with Pro/Pro had an increased odds of developing prostate cancer compared to those with Arg/Arg (32). Similar to our result, no association was found in meta-analysis of p53 Codon 72 Arg>Pro polymorphism with cancer odds in Saudi and Indian population in all genetic models (33-35). This meta-analysis had some limitations. First, in the present study the p53 Codon 72 Arg/Pro polymorphism, which might have influenced the odds of cancer in combination with other genetic polymorphisms (gene-gene and gene-environment interaction), was not considered. Second, we found heterogeneity in the overall analysis. Third, our meta-analysis was based on unadjusted estimates, while a more precise analysis could be performed if individual data were available that would allow for an adjustment estimate (by age and sex). Despite these limitations, our meta-analysis had several strengths. First, the number of studies included in the analysis was relatively large. Second, we included studies published in English and Persian languages that covered all Iranian based publications.

\section{Conclusion}

A meta-analysis is an approach of statistical analysis, 
which combines both statistically notable and none- statistically notable results from individual studies to improve statistical efficiency by enlarging the sample size. Our results revealed that p53 Codon 72 Arg>Pro polymorphism may considerably modulate the overall cancer odds among Iranian population.

\section{Acknowledgement}

This work was financially supported by Kurdistan University of Medical Sciences, Sanandaj, Iran.

\section{Conflict of Interests}

The authors declare that they have no competing interests.

\section{References}

1. Jemal A, Bray F, Center MM, Ferlay J, Ward E, Forman D. Global cancer statistics. CA Cancer J Clinic. 2011;61(2):69-90.

2. Pharoah PD, Dunning AM, Ponder BA, Easton DF. Association studies for finding cancer-susceptibility genetic variants. Nat Rev Cancer. 2004;4(11):850-60.

3. Zhou X, Gu Y, Zhang SL. Association between p53 codon 72 polymorphism and cervical cancer risk among Asians: a HuGE review and meta-analysis. Asian Pac J Cancer Prev. 2012;13(10):4909-14.

4. Dulić V, Kaufmann WK, Wilson SJ, Tisty TD, Lees E, Harper JW, et al. p53-dependent inhibition of cyclin-dependent kinase activities in human fibroblasts during radiation-induced G1 arrest. Cell. 1994;76(6):1013-23.

5. Woods DB, Vousden KH. Regulation of p53 function. Exp cell Res. 2001;264(1):56-66.

6. Greenblatt M, Bennett W, Hollstein M, Harris C. Mutations in the p53 tumor suppressor gene: clues to cancer etiology and molecular pathogenesis. Cancer Res. 1994;54(18):4855-78.

7. Oren M. Decision making by p53: life, death and cancer. Cell Death Differ. 2003;10(4):431-42.

8. Ghasemi N, Karimi-Zarchi M, Mortazavi-Zadeh MR, Atash-Afza A. Evaluation of the frequency of TP53 gene codon 72 polymorphisms in Iranian patients with endometrial cancer. Cancer genet cytogenet. 2010;196(2):167-70.

9. Khadang B, Fattahi MJ, Talei A, Dehaghani AS, Ghaderi A. Polymorphism of TP53 codon 72 showed no association with breast cancer in Iranian women. Cancer genet cytogenet. 2007;173(1):38-42.

10. Doosti A, Zamani M, Dehkordi PG, Taheri S, Banitalebi M, Mahmoudzadeh M. Association of the p53 codon 72 polymorphism with colorectal cancer in South West of Iran. Scient. Res. Essays. 2011;6(15):3148-52.

11. Behfarjam F, Rostamzadeh J, Zarei MA, Nikkhoo B. Association of Two Polymorphic Codons in P53 and ABCC1 Promoter with Prostate Cancer. Iran J Biotechnol. 2015;13(1):49-54.

12. Yaghmaei M, Salimi S, Namazi L, Farajian-Mashhadi F. Association of XRCC1 Arg399GIn and Tp53 Arg72Pro polymorphisms and increased risk of uterine leiomyoma-A case-control study. Genet. Mol. Biol. 2015;38(4):444-9.

13. Mojtahedi Z, Hashemi SB, Khademi B, Karimi M, Haghshenas MR, Fattahi MJ, et al. p53 codon 72 polymorphism association with head and neck squamous cell carcinoma. Braz $\mathrm{j}$ Otorhinolaryngology. 2010;76(3):316-20.

14. Dehghan R, Feizi MAH, Pouladi N, Babaei E, Montazeri V, Fakhrjoo A, et al. Association of P53 (- 16ins-Pro) Haplotype with the Decreased Risk of Differentiated Thyroid Carcinoma in Iranian-Azeri Patients. Pathol Oncol Res. 2015;21(2):449-54.

15. Kazemi M, Salehi Z, Chakosari RJ. TP53 codon 72 polymorphism and breast cancer in northern Iran. Oncol.Res.Feat. Prec. Clin. Cancer Therap. 2009;18(1):25-30.

16. van Heemst D, Mooijaart SP, Beekman M, Schreuder J, de Craen AJ, Brandt BW, et al. Variation in the human TP53 gene affects old age survival and cancer mortality. Exp Gerontol. 2005;40(1):11-5.

17. Dumont P, Leu J-J, Della Pietra AC, George DL, Murphy M. The codon 72 polymorphic variants of p53 have markedly different apoptotic potential. Nat Genet. 2003;33(3):357-65.
18. Pim D, Banks L. p53 polymorphic variants at codon 72 exert different effects on cell cycle progression. Int $\mathrm{J}$ Cancer. 2004;108(2):196-9.

19. Jiang N, Pan J, Wang L, Duan YZ. No significant association between 533 codon $72 \mathrm{Arg} /$ Pro polymorphism and risk of oral cancer. Tumor Biol. 2013;34(1):587-96.

20. Wang S, Lan X, Tan S, Wang S, Li Y. P53 codon 72 Arg/Pro polymorphism and lung cancer risk in Asians: an updated metaanalysis. Tumor Biol. 2013;34(5):2511-20.

21. Zhou Y, Li N, Zhuang W, Liu GJ, Wu TX, Yao X, et al. P53 codon 72 polymorphism and gastric cancer: A meta-analysis of the literature. Int J Cancer. 2007;121(7):1481-6.

22. Irshad M, Mandal RK, Al-Drees A, Khalil MS, Abdulghani HM. No Evidence of Association of the Arg72Pro p53 Gene Polymorphism with Cancer Risk in the Saudi Population: a Meta-Analysis. Asian PacJ Cancer Prev. 2015;16(14):5663-7.

23. Mandal RK, Yaday SS, Panda AK, Khattrib S. Insertion/deletion polymorphism of the ACE gene increased risk of Behcet disease: evidence from a meta-analysis. Ann Saudi Med. 2013;33(5):437.

24. Dastjerdi MN, Salehi M, Mohajeri MR, Morsali F, Sadeghi HM, Esfandiary E. Evidence for an association of TP53 codon 72 polymorphism with sporadic colorectal cancer risk in Isfahan. J Res Med Sci. 2008;13(6):317-23.

25. Shen H, Zheng Y, Sturgis EM, Spitz MR, Wei Q. P53 codon 72 polymorphism and risk of squamous cell carcinoma of the head and neck: a case-control study. Cancer Lett. 2002;183(2):123-30.

26. Lane DP. Cancer. p53, guardian of the genome. Nature. 1992;358:15-6.

27. Storey A, Thomas M, Kalita A, Harwood C, Gardiol D, Mantovani $\mathrm{F}$, et al. Role of a p53 polymorphism in the development of human papilloma-virus-associated cancer. Nature. 1998;393(6682):229-34.

28. Gohari-Lasaki S, Gharesouran J, Ghojazadeh M, Montazeri V, Mohaddes AS. Lack of Influence of TP53 Arg72Pro and 16bp Duplication Polymorphisms on Risk of Breast Cancer in Iran. Asian Pac J Cancer Prev. 2014;16(7):2971-4.

29. Mojtahedi Z, Haghshenas M, Hosseini S, Fattahi M, Ghaderi A. p 53 codon 72 polymorphism in stomach and colorectal adenocarcinomas in Iranian patients. Indian J Cancer. 2010;47(1):31.

30. Pezeshki A, Sari-Aslanl F, Ghaderi A, Doroudchi M. p53 codon 72 polymorphism in basal cell carcinoma of the skin. Pathol. Oncol. Res. 2006;12(1):29-33.

31. Doosti A, Dehkordil P, Davoudi N. A p53 codon 72 polymorphism associated with breast cancer in Iranian patients. Afr $\mathrm{J}$ Pharm Pharmacol. 2011;5:1278-81.

32. Babaei F, Ahmadi SA, Abiri R, Rezaei F, Naseri M, Mahmoudi M, et al. The TP53 codon 72 polymorphism and risk of sporadic prostate cancer among Iranian patients. Iran j pub health. 2014;43(4):453.

33. Irshad M, Mandal R, Al-Drees A, Khalil M, Abdulghani H. No Evidence of Association of the Arg72Pro p53 Gene Polymorphism with Cancer Risk in the Saudi Population: a Meta-Analysis. Asian Pac J Cancer Prev. 2014;16(14):5663-7.

34. Mandal RK, Yadav SS, Panda AK. No evidence of correlation between p53 codon $72 \mathrm{G}>\mathrm{C}$ gene polymorphism and cancer risk in Indian population: a meta-analysis. Tumor Biol. 2014;35(9):8607-13.

35. Eydian Z, Asna'ashari A, Behravan J, Sharifi-Rad J, Heravi RE. Cell Mol Biol. 2016. 